\title{
The results of studies on the extension of methodological capabilities of determining physico-chemical conditions of lead-based liquid-metal coolants
}

\author{
Sergey V. Salaev ${ }^{1}$, Radomir Sh. Askhadullin ${ }^{1}$, Konstantin D. Ivanov ${ }^{1}$, Alexandr Yu. Legkikh ${ }^{1}$, \\ Said-Ali S. Niyazov ${ }^{1}$ \\ 1 JSC “SSC RF - IPPE” n.a. A. I. Leypunsky, 1, Bondarenko square, Obninsk, Kaluga region, 249033 Russia \\ Corresponding author: Konstantin D. Ivanov (ivanovkd100@yandex.ru)
}

Academic editor: Yury Kazansky • Received 21 August 2019 • Accepted 10 April 2020 Published 19 June 2020

Citation: Salaev SV, Askhadullin RSh, Ivanov KD, Legkikh AYu, Niyazov S-AS (2020) The results of studies on the extension of methodological capabilities of determining physico-chemical conditions of lead-based liquid-metal coolants. Nuclear Energy and Technology 6(2): 71-75. https://doi.org/10.3897/nucet.6.54626

\begin{abstract}
The authors consider examples of using the thermal cycling method for heavy lead- and lead-bismuth-based coolants with simultaneous measurement of the thermodynamic activity (TDA) parameter of oxygen impurities. In these experiments, structural EI852 and EP823 ferritic-martensitic steels as well as EP302 austenitic steel were used as sources of iron impurities.

As a result of the experiments, it was found that iron oxides previously formed in the coolant, as such or in the form of an oxide film on the structural steels, are not inert phases in heavy coolants, but can exchange iron and oxygen with the melt. The nature of this exchange depends both on the actual coolant impurity state and on external conditions, including, first of all, temperature.

The experimental data obtained by thermal cycling of lead- and lead-bismuth coolants were analyzed both in the region of relatively high oxygen TDA values close to the oxygen saturation concentration and in the region of sufficiently low values of this parameter close to the saturation concentration of iron impurities.

It is concluded that the proposed coolant thermal cycling method is informationally significant and can be recommended for further use, for example, to obtain quantitative data on the content of iron impurities in the coolant.
\end{abstract}

\section{Keywords}

Mass transfer, coolant, lead, lead-bismuth, structural steel, oxide film, oxygen, iron, thermodynamic activity, mass content of impurity, oxygen activity sensor

\section{Introduction}

The direct entry of structural steel components into the coolant in the presence of protective passivation coatings on the surface of these steels, in contrast to liquid metal corrosion processes, where the steel components dissolve in the coolant, is a complex multistage process of diffusion and interaction of steel and oxygen components. This process takes place simultaneously in the steel itself, on the inner boundary of the oxide film, in the volume oc-

* Russian text published: Izvestiya vuzov. Yadernaya Energetika (ISSN 0204-3327), 2020, n. 1, pp. 98-106.

Copyright Salaev SV et al. This is an open access article distributed under the terms of the Creative Commons Attribution License (CC-BY 4.0), which permits unrestricted use, distribution, and reproduction in any medium, provided the original author and source are credited. 
cupied by the oxide coating, on the outer border between the oxide layer and the coolant and directly in the coolant itself. This is a complex interconnected process (Gromov and Shmatko 1997, Martinelli and Balbaud-Célérier 2011, Mulier 2008), in which the physicochemical state of the liquid metal melt is of great importance. To determine it, it was common practice to use the method of taking samples and their subsequent analysis for the content of oxygen and metallic impurities. But this method was practically abandoned due to its relatively low sensitivity to dissolved oxygen and insufficient information content on the main products of the interaction between the coolant and structural steels. At the same time, taking into account the importance of monitoring the oxygen conditions of the coolant, oxygen thermodynamic activity sensors have come into common use. This is a significantly more sensitive means of monitoring the coolant condition for the oxygen impurity. However, unlike the sampling procedure, where the mass content of this impurity is determined, the relationship between the oxygen TDA and its mass content is uniquely determined only for the coolant refined from other impurities. This relationship is tabulated for both lead- and lead-bismuth coolants. In the well-known $E-T$ diagram, which relates the readings of the sensor $E$ and the temperature of the coolant $T$, this tabulated dependence represents for each oxygen concentration a straight line, which at low temperatures can go into another line characterizing the ultimate solubility of oxygen and the formation of the corresponding excess solid coolant oxide. However, with changes in the coolant physicochemical condition due to the emergence of other impurities in it, in particular iron as the main component of steels, the nature of the temperature dependence of the readings of the oxygen TDA sensors changes significantly, which is the basis for using this technique for a more detailed analysis of the coolant real condition.

\section{Analysis of temperature dependen- cies of changes in oxygen thermo- dynamic activity}

In the region of sufficiently low oxygen TDA (low oxygen partial pressures), the problem of identifying a "ferruginized" coolant does not present any particular difficulties, since, in this region, the temperature-dependent changes in the sensor's EMF are qualitatively different from the "isoconcentration" distribution. As practice shows, with oxygen thermodynamic activities at oxygen TDA levels of $a \leq 10^{-3}$, the maintained "isoconcentration" dependence of the sensor readings is more likely an exception than a rule.

It is much more difficult to distinguish between these two states in the region of partial oxygen pressures, which are close to the release of the excess solid oxides from the coolant. At present, it is generally accepted that the "isoconcentration" temperature dependence of the sensor readings in this region is fulfilled, and when the tempe- rature decreases, the $\mathrm{PbO}$ phase is released (Chernov et al. 2003, Askhadullin et al. 2003). In other words, the iron impurity goes into the oxidized state and becomes inert with respect to the lead melt and oxygen in it.

At the same time, it often turns out that in the region of $\sim 400-600{ }^{\circ} \mathrm{C}$, the sensor readings stabilize at a temperature drop of $E \sim 120-125 \mathrm{mV}$, followed by a slight increase with a further decrease in $T$.

This contradicts thermodynamic calculations, according to which the potential of the $\{\mathrm{Pb}\}-<\mathrm{PbO}>$ system has a small negative temperature slope and stabilizes in the considered temperature range at a level of $E \sim 110$ $108 \mathrm{mV}$. These deviations may seem insignificant if we do not know that, in this region of changes in the sensor readings, the price of each millivolt in the mass of dissolved oxygen is extremely high. Factually, this refers to the impact of iron impurities on the solubility of oxygen in the lead coolant. Thus, for a pure $\{\mathrm{Pb}\}-<\mathrm{PbO}>$ system, in the range of the oxygen activity sensor (OAS) readings $E=120-108 \mathrm{mV}$, the melt must absorb up to $90 \%$ of the oxygen mass of the saturation concentration (as calculated in (Ivanov et al. 2005)).

At one time, attempts were made to explain the observed deviations of the sensor readings at the equilibrium level of the coolant with the oxide phase by various factors (the influence of the thermoelectric power, pollution of the sensors, etc.). However, the data on the level of equilibrium in the "coolant-oxide phase" system (120-125 mV) were systematic and recorded by various sensors. At the same time, steel was always present in the system. Meanwhile, a previous analysis of the observed differences in the readings of two TDA oxygen sensors with different reference electrodes $\left(\{\mathrm{Pb}\}-<\mathrm{PbO}>\right.$ and $\left.\{\mathrm{Bi}\}-<\mathrm{Bi}_{2} \mathrm{O}_{3}>\right)$ in the same medium showed a stable level of $108 \mathrm{mV}$, which corresponds to the thermodynamic calculations in (Ivanov et al. 2002).

Indicative in this regard is also the nature of EMF changes of the same sensor in the experiments with a rotating disk, carried out when EI852 steel samples were tested in lead- and lead-bismuth coolants. In the initial period (after the sample rotation was established), characterized by an increase in the interaction of the liquid metal melt with atmospheric oxygen, a regular decrease in the sensor readings was recorded: in lead, at $620^{\circ} \mathrm{C}$, from $124-122 \mathrm{mV}$ to $\sim 110 \mathrm{mV}$ and in lead-bismuth, at $620^{\circ} \mathrm{C}$, from $\sim 125 \mathrm{mV}$ to $\sim 77 \mathrm{mV}$. As slag accumulated on the surface of the melt (which was observed visually), the OAS readings increased to $E \sim 115 \mathrm{mV}$ in lead and to $E \sim 79 \mathrm{mV}$ in lead-bismuth. The experiments were carried out in metal cups made of 0X18H10T steel, which did not exclude the release of metal components directly into the coolant. Therefore, these results were interpreted as a dynamic balance of deoxidation and oxidation processes with a constant supply of iron from the steel and oxygen from the atmosphere.

Thus, the data presented indicate a qualitative change in the coolant condition in the presence of an iron source not only in the "deoxidized" region but also in the range of oxygen activity close to unity. 
To confirm this thesis, experiments were carried out to identify the nature of changes in the potential of the melt in the state of its equilibrium with the resulting solid phase. For this purpose, the lead melt was periodically cycled during the exposure of EP823 steel samples in it at a base temperature of $620^{\circ} \mathrm{C}$.

Before the steel samples were immersed, the lead melt was previously refined in air, and the resulting slag was removed from its surface. The surface of the samples was relatively small $\left(37 \mathrm{~cm}^{2}\right)$, and a ceramic cup $\left(\mathrm{Al}_{2} \mathrm{O}_{3}\right)$ was used as a lead container. All this allowed us to hope that, at the beginning of the exposure of the samples, the melt did not contain metallic impurities in appreciable amounts.

Figure 1 shows the changes in the OAS readings during the melt cooling at certain time intervals (campaign with EP823 steel). The obtained dependences indicate that in the initial period of steel exposure, as expected, the state of the melt was close to refined. It should be noted that, in this case, the sensor EMF level corresponded to the calculated values $(E \sim 108-110 \mathrm{mV})$. Subsequently, a gradual departure from the initial level was observed, associated with the entry of iron into the melt. Due to the small contact surface of the coolant with the steel as well as low diffusion fluxes of iron through the oxide film formed on the EP823 steel samples, the potential change process took quite a long time $(\sim 760 \mathrm{~h})$. The level of the sensor readings reached at this point of time during the separation of the solid oxides in the melt cooling process was $E \sim 120-124 \mathrm{mV}$.

A much more rapid coolant "ferruginization" was observed in the experiments with EP302 steel, in which the contact surface of the steel with the coolant was $189 \mathrm{~cm}^{2}$, and the amount of lead was approximately two times less (Fig. 2). The first thermal cycling of the coolant was carried out immediately following the passivation after 17 hours of exposure of the EP302 steel samples in the lead melt. The minimum values of the sensor readings were $E \sim 110 \mathrm{mV}$, but during further cooling they increased to 115-117 mV. After about 150 hours of exposure, the

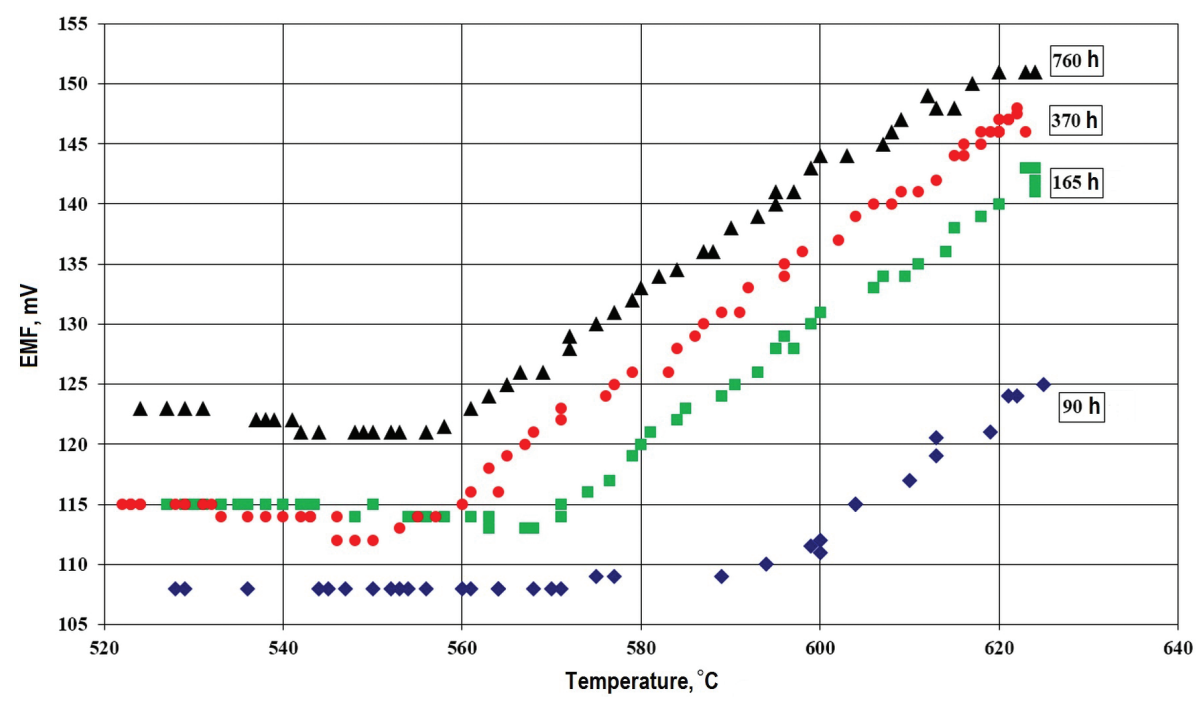

Figure 1. Temperature dependence of the OAS readings in the melt cooling process during the experiments with EP823 steel.

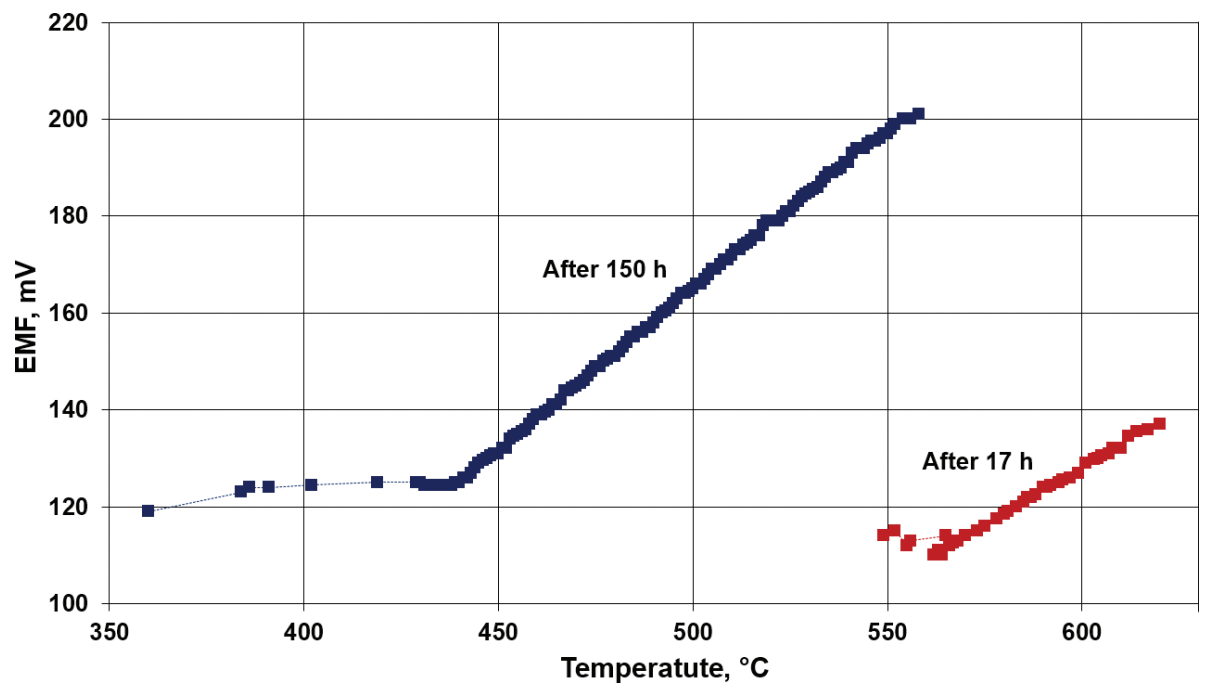

Figure 2. EMF temperature dependence of the OAS readings in the melt cooling process during the experiments with EP823 steel. 
precipitation of the solid oxide was recorded already at the level of $E \approx 120-124 \mathrm{mV}$.

The experiments show that, over time, the liquid metal is saturated with iron, and the solid phase formed during the cooling process is not pure lead oxide but, probably, is complex oxide with one or another iron content.

It is logical to assume that the impact of iron impurities in a varying degree should also be manifested in the region of intermediate oxygen activities in the coolant (relatively far from the equilibrium line $<\mathrm{Fe}>-<\mathrm{Fe}_{3} \mathrm{O}_{4}>$ and the equilibrium line $\{\mathrm{Pb}\}-<\mathrm{PbO}>$ ) and, moreover, in the area of activities directly adjacent to the line $<\mathrm{Fe}>-<\mathrm{Fe}_{3} \mathrm{O}_{4}>$.

To analyze this effect, it is more convenient to use coordinates, where the $\lg p_{\mathrm{O} 2}$ values are considered along the ordinate axis and the $\left(\lg p_{\mathrm{O} 2}, 1 / T\right)$ values are considered along the abscissa axis. The partial pressure of molecular oxygen in equilibrium with the oxygen dissolved in the melt, depending on the sensor readings and temperature, are calculated by the formula:

$\lg \left(p_{\mathrm{O} 2}{ }^{\text {melt }}, \mathrm{atm}\right)=-20609 / T+10.188-\mathrm{F} \cdot N_{e} \cdot E /(19.147 \cdot T)$,

where $-20609 / T+10,188$ is the partial pressure logarithm of molecular oxygen $\left(\lg p_{\mathrm{O} 2}\right)$ in the reference electrode $\mathrm{Bi}-\mathrm{Bi}_{2} \mathrm{O}_{3} ; \mathrm{F}=96,485$ is the Faraday constant, C/ mol; $N_{e}=4$ is the number of electrons participating in the transfer; $E$ denotes the OAS readings, $\mathrm{mV} ; T$ is the temperature, $\mathrm{K}$.

Figure 3 shows the calculated temperature dependences of the constant oxygen concentration for a pure $\{\mathrm{Pb}\}-<\mathrm{P}-$ $\mathrm{bO}>$ system with a constant oxygen content in the melt (from $10^{-4}$ to $10^{-6.5}$ atomic fractions). The approximation dependences presented on the graph show that they in the coordinates $\left(\lg p_{\mathrm{O} 2}, 1 / T\right)$, in contrast to the coordinates $(E$, $T$ ), have a practically constant temperature slope (from -13541 to -13545 ), which determines their convenient use.

The experimentally observed deviations from the temperature slope indicated for a pure system should charac- terize the degree of the impact of iron on the lead melt oxidation potential. The iron available in the coolant or coming from the source consumes part of the oxygen available in the melt. As a consequence, the temperature slope in such a system should increase. If dissociation or conversion of any oxides with the release of free oxygen into the melt proceeds in the system, then the temperature coefficient should decrease in absolute terms.

Figure 4 shows the results of measuring the system oxygen potential in the coolant cooling process obtained during the EP302 steel campaign. Changes in the melt oxygen potential were observed only in transitional regimes of temperature changes to lower values at the end of the campaign when the experiments were completed. Of great interest to us are the results of the final melt cooling (during 923 hours after the campaign started). The graph shows that with the onset of cooling, the temperature dependence of the partial pressure first approaches the equilibrium line $\left.\langle\mathrm{Fe}\rangle-<\mathrm{Fe}_{3} \mathrm{O}_{4}\right\rangle$, then it practically coincides with it and, at a temperature of $\sim 450{ }^{\circ} \mathrm{C}$, sharp evolution of oxygen into the coolant begins, accompanied by the corresponding increase in $p_{\mathrm{O} 2}$. The process of oxygen evolution at a slower pace continues until the melt freezes.

The results obtained confirm that, under appropriate conditions, iron oxides in heavy lead-containing coolants can dissociate. This is apparently due to the lack of iron in the coolant necessary for the further oxide formation. The decomposition of iron oxides by this mechanism is accompanied by the release of oxygen in accordance with the stoichiometry of these oxides.

Thus, it was found that iron oxides previously formed in the coolant, as such or in the form of an oxide film on the structural steels, are not inert phases in heavy coolants, but can exchange iron and oxygen with the melt. The nature of this exchange depends both on the actual coolant impurity state and on external conditions, including first of all, temperature.

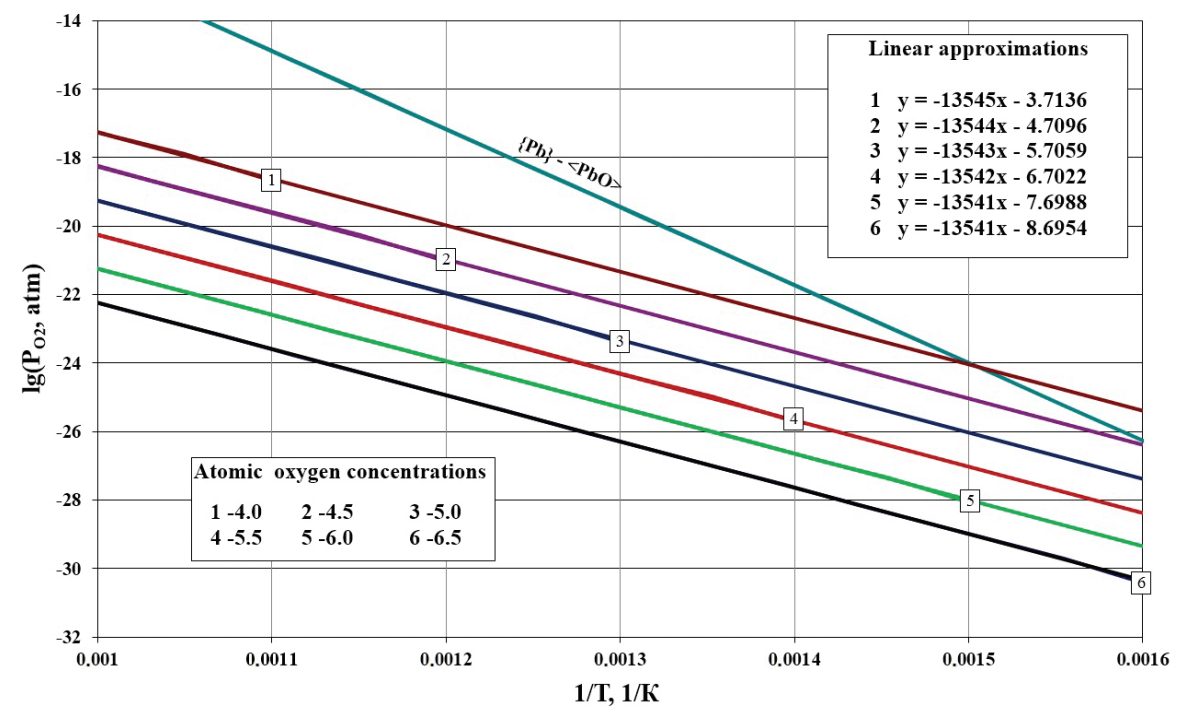

Figure 3. Calculated temperature dependences of a constant oxygen concentration for the pure $\{\mathrm{Pb}\}-<\mathrm{PbO}>$ system. 


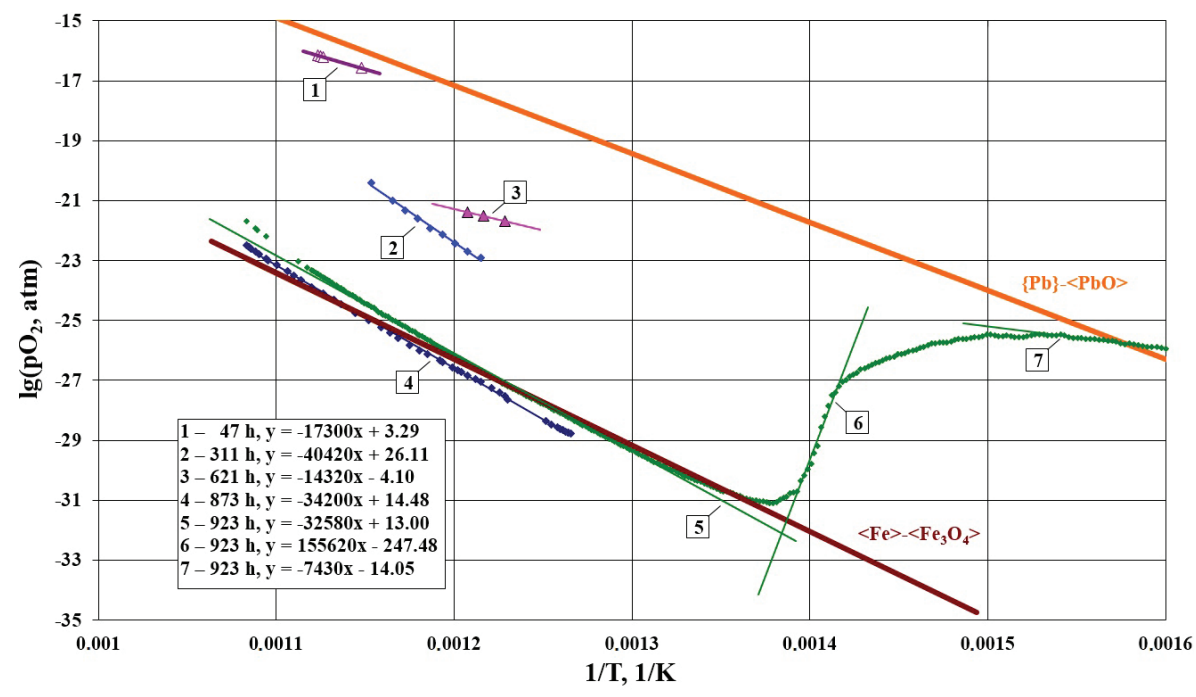

Figure 4. Temperature dependence of the oxygen partial pressure in the melt cooling process in the experiments with EP823 steel.

\section{Conclusion}

The authors considered examples of using the thermal cycling technique for heavy lead- and lead-bismuth-based coolants in order to obtain additional information about their actual physicochemical state based on the analysis of the oxygen thermodynamic activity behavior.

\section{References}

- Askhadullin RSh, Martynov PN, Sysoev YuM (2003) Oxygen Thermodynamic Activity Control in Lead and Lead-Bismuth Coolants by the Oxides Dissolution Method. Proc. of the Conference on Heavy Liquid Metal Coolants in Nuclear Technologies (HLMC-2003). Obninsk. SSC RF-IPPE Publ., pp. 82. [in Russian]

- Chernov ME, Martynov PN, Gulevsky VA (2003) Development of Electrochemical Oxygen Sensor of the Capsular Type for Monitoring and Control of the Heavy Coolant State. Proc. of the Conference on Heavy Liquid Metal Coolants in Nuclear Technologies (HLMC2003). Obninsk. SSC RF-IPPE Publ., pp. 85. [in Russian] https:// link.springer.com/article/10.1007/s10512-005-0215-5 [accessed Aug 17, 2019]

- Gromov BF, Shmatko BA (1997) Oxidation Potential of Lead and Bismuth Melts. Izvestia vuzov. Yadernaya Energetika. [News of Higher Education Institutions. Nuclear Power Engineering.], 6: 14-18. [in Russian]

- Ivanov KD, Lavrova OV, Martynov PN (2002) Thermodynamics of $\mathrm{Pb}-\mathrm{O}$ System and Solubility of Oxygen in Lead Melt. Proc. of the
It is shown that the proposed coolant thermal cycling method is informationally significant and can be recommended for further use, for example, to obtain quantitative data on the content of iron impurities in the coolant.
Conference on Problems of Technology and Thermal Hydraulics of Liquid-Metal Heat Carriers. Obninsk. SSC RF-IPPE Publ. [in Russian]

- Ivanov KD, Lavrova OV, Salaev SV (2005) The Use of the Developed Technique for Estimation of Metal Components Diffusion Yield from Steels to Study Corrosion Resistance of These Steels in Heavy Coolants. Proc. of the Conference on Thermo-Hydraulic Safety Aspects of NPPs with Fast Reactors. Obninsk. SSC RF-IPPE Publ., pp. 117. [in Russian]

- Martinelli L, Balbaud-Célérier F (2011) Modelling of the Oxide Scale Formation on Fe-Cr Steel During Exposure in Liquid Lead-bismuth Eutectic in the $450-600{ }^{\circ} \mathrm{C}$ Temperature Range. Materials and methods, 62: 531-542. https://doi.org/10.1002/maco.201005871

- Mulier G (2008) Status on Liquid Metal Corrosion, Mechanical Properties and Corrosion Protection Research at FZK and in Collaboration with Partners. Proc. of the Conference on Heavy Liquid Metal Coolants in Nuclear Technologies (HLMC-2008). Obninsk. SSC RF-IPPE Publ., pp. 20. 